\title{
Empowering academics to be adaptive with eLearning technologies: An exploratory case study
}

\author{
Helen Flavell, Courtenay Harris, Connie Price, Emma Logan, Sunila Peterson \\ Curtin University
}

\begin{abstract}
This paper describes an exploratory case study investigating the capacity of a multidisciplinary approach to academic development, to empower adaptive responses to ongoing technological change impacting on teaching practice. A quasi-experimental design with an intervention group $(n=22)$ and a comparative control group $(n=7)$ was adopted. Pre and post online questionnaires were administered to participants in both groups to evaluate attitudes and experiences relating to technology use in teaching and learning. The questionnaires were adapted from the Technology Acceptance Model. Qualitative measurement of the intervention group's experiences following the professional development was captured using semi-structured interviews, followed by two focus groups to confirm the interview findings. Results indicate that the professional development impacted positively on participants through significantly increased levels of confidence and perceived ease of use. Qualitative data indicated participants experienced cognitive, emotional, and/or practical changes during and/or following the professional development.
\end{abstract}

\section{Introduction}

Change and disruption are constant across all industry (The Institute for the Future, 2017) and higher education is not immune to the impact of technology and globalisation affecting other sectors (Price Waterhouse Coopers and Australian Higher Education Industry Association, 2016). A recent publication by the Melbourne Centre for the Study of Higher Education, for example, highlights the need for tertiary leaders to ensure their institutions are responsive, agile with the capacity to adapt to the rate of change characterised by the twenty-first century (Adams Becker et al., 2017). Teaching and learning have undergone significant changes to practice with a high rate of technological disruption (Barber, Donnelly, \& Rizvi, 2013). These include, but are not limited to, Web 2.0 technologies (e.g., blogs, podcasts, wikis, social media, and polling applications), learning, curriculum, student and academic integrity administration systems, eBooks, gamification, videos, ePortfolios, and electronic marking. In addition, academics are required to use a broad range of generic information and communications technology (ICT) in carrying out their daily work (Bukari, 2016). Web 3.0 and the Internet of Things suggest that the technological disruption will continue. Furthermore, academics will need to understand, interpret and apply learning analytics to improve the student experience (Arroway, Morgan, O'Keefe, \& Yanosky, 2016).

Whilst it is important not to collapse change and technology, they are inextricably linked in higher education teaching and learning, with effective technology uptake often central to institutional responses to external drivers (Blin \& Munro, 2008). The flipped classroom, for example, illustrates how growing student numbers, increasing competition, massive open online courses (MOOCs), and eLearning technologies are requiring universities and academics to reconsider how they can best utilise technology to support student learning with declining resources and less teaching contact time (Davis, 2013). The role of the academic has thus changed from sage on the stage and guide on the side, to meddler in the middle, with significant implications for identity and work practices (McWilliam, 2009; Muzyka \& Luker, 2016; Sadler, Selkrig, \& Manthunga, 2017).

Academics are required to adapt positively to changes resulting from technology, yet professional development approaches have typically focussed on mastery and how to use individual applications and platforms (Bukari, 2016; Sharpe \& Oliver, 2007). Some training involves relevant pedagogies, but much is delivered by those skilled in ICT rather than those with knowledge of educational practice, academic identity, leadership, and change management. Increasingly, ICT and eLearning training is offered online (Rienties, Brouwer, \& Lygo-Baker, 2013) and is often centralised and dislocated from practice, and unless there is an opportunity to apply the learning immediately there can be a lack of skill transfer. According to one study of over 1,000 academics in Gipuzkoa, Spain, most faculty members appear not to be accessing the ICT training offered; instead, they are self-taught and/or rely on peer learning (Lareki, Ignacio, de Morentin, \& Amenabar, 2010). As Sharrock (2017) argues, the pressing need for universities to be agile 
and responsive to survive in a rapidly changing environment is often at odds with common practices in higher education. Is it possible, therefore, that current professional learning for technologies may require rethinking? Academics_regardless of whether they are not in formal leadership positions_now require integrated development opportunities that recognise the complexities and diversity of their roles across multiple domains and competing priorities (Vilkinas, Leask, \& Ladyshewsky, 2009) which support their capacity to be agile, creative, and responsive as academic work is reimagined (Sadler et al., 2017).

It is important to remember, however, that whilst change and the disruption brought about by technology are now constant in the Australian and international tertiary sectors, there are ideological debates underway about the value and impact of change on the role of the university and academic work and identity (e.g., the special issue of Higher Education Research and Development [Peseta, Barrie, \& McLean, 2017]). Similarly, Bayne (2015) argues that technology is not ideologically neutral and requires ongoing interrogation. These highly critical stances are in opposition to much of the grey literature on technology uptake in higher education which is largely uncritical and celebratory (e.g., the current buzz associated with the flipped classroom and learning analytics) with the (overused) discourse of innovation strongly aligned with technology adoption (Winslett, 2014). Critical interrogation of the changes wrought on higher education is essential to imagining ways to interrogate, for example, the relevance of certain eLearning technologies and their value to student outcomes (Abeysekera \& Dawson, 2015). At the same time, however, change and the impact of technology is unlikely to subside. If the past 5 years are anything to go by, as in all aspects of our life, the pace of change resulting from developments in technology will increase (Bakhshi, Frey, \& Osborne, 2015). If this is, indeed, the context in which we now live and work, how can universities empower academics to adapt to new technologies and build their capacity to survive a world in flux?

\section{Faculty acceptance of technologies}

The literature on technology uptake suggests that-with the exception of champions or early adoptersmany academics are slow to embrace new technologies due to a range of issues (Johnson, Winiewski, Kuhlemeyer, Issacs, \& Krzykowski, 2012; Watty, McKay, \& Ngo, 2016). For example, risks associated with their potential failure (Howard, 2013), their perceived value/relevance (Debuse, Lawley, \& Shibl, 2008), workload and time constraints (Wingo, Ivankova, \& Moss, 2017), a lack of confidence (Dusick \& Yildirim, 2000), general technology anxiety (Johnson et al., 2012), as well as a lack of resources/support and constant new technologies to master (Adams Becker et al., 2017 ; Birch \& Burnett, 2009; McNutt, 2010; Wingo et al., 2017). There is, therefore, a tendency for academics to be represented in the literature as technology resisters (e.g., Birch \& Burnett, 2009; Deneen \& Boud, 2013; Hansen, 2009; Rienties et al., 2013). However, as has been argued, this perceived resistance could result from a lack of adequate rationale for change. Rarely are academics given the why, instead they are merely told that they must implement new technologies (Batson, 2011). With academics known for their skepticism, change management in higher education requires skillful leadership (Wilson-Medhurst, Blair, \& Monnet, 2017). According to Englund, Olofsson, and Price (2017), whilst educational technology has been lauded as having the potential to transform teaching and learning this has not fully eventuated and there is a need for further research to investigate what has been described as the digital disconnect. In their study, they argue that academic attitudes and beliefs play a major role in the effective adoption of eLearning (Englund et al., 2017).

Research into technology uptake in higher education has largely been informed by the technology acceptance model (TAM) (Davis, 1989) and the unified theory of acceptance and use of technology (UTAUT) (Venkatesh, Morris, Davis, \& Davis, 2003; Wingo et al., 2017). Generally, in the field of education, studies have focused on the factors that influence technology acceptance amongst teachers and students (Drent \& Meelissen, 2008; Teo, 2011). What is significant about these studies is that they identified the perceived ease of use as a major factor in the successful uptake of technological innovations (Agarwal \& Prasad, 1997). Certainly, according to the literature academic attitudes to, and beliefs about, technology (e.g. anxiety, confidence and perceived relevance) appear to play a role in how technologies are embedded in teaching practice (Dusick \& Yildirim, 2000). Given the oft reported influence of academic attitudes and beliefs on technology uptake, this paper describes an exploratory case study (Yin, 2009) designed to investigate the capacity of a multidisciplinary approach to academic development, underpinned by distributed leadership (Gronn, 2002), to empower adaptive responses to ongoing technological change impacting on teaching practice. Ultimately, the development opportunity hoped to build participants’ 
resilience and capacity for agile teaching within a rapidly changing tertiary context. The specific research questions for the study were:

a) What impact did the agile teaching professional development have on participants' beliefs, perceptions of, and attitudes toward, learning technologies?

b) Were there any changes in behaviour resulting from participation in the professional development? and

c) If so, what changes occurred?

\section{Background and approach to designing the professional development}

Through a review of the literature, the phrase agile teaching (Allen, 2009) was embraced to symbolise the development approach. The phrase originated from Razmov and Anderson (2006), who borrow "'agile' from software development that emphasises short feedback cycles, flexibility, and direct involvement of the customer" (Allen, 2009). The correlation with a constructivist approach to teaching is evident with the emphasis on regular feedback, flexibility, and a student-centred approach. Allen applied Razmov's agile teaching to the adaptive use of Web 2.0 technologies in higher education, he states:

Being an agile teacher means staying true to your purpose, fixed in your intent to provide excellence in education but always adapting and adopting new methods of achieving that goal and where prompted to by changes in the world around you: the internet demonstrates how agility is now a key aspect of knowledge work—make it part of your teaching (Allen, 2009.

This terminology_agile teaching-along with an emphasis on flexible, student-centred practice underpinned the philosophy of the professional development.

Although there is a clear need for teaching staff to adapt effectively to eLearning from a policy or organisational change perspective, the development workshop explored here was devised and enacted within a particular teaching and learning practice in a large faculty of health at an Australian university. Specifically, the idea for the agile teaching professional development grew from challenges to embedding an eMarking strategy involving electronic analytical rubrics using iPads in a large core first-year unit with over 3,000 students in a semester and 40 tutors (Brewer, Flavell, Davis, Harris, \& Bathgate, 2014). The teaching team was almost entirely made up of casual tutors with the remainder on permanent or fixed-term contracts. Even with thoughtful workflow management and training the introduction of eMarking faced challenges to adoption. Through a collaboration between the unit coordinator $(\mathrm{CH})$, the manager of assessment at the central teaching and learning unit (CP) and the coordinator of the scholarship of teaching and learning in the faculty of health (HF) the workshop evaluated here was created by drawing on the leadership literature and the team's collective experience in a range of work and personal contexts. Rather than being devised and delivered centrally and focused on mastery of a single technology, the agile teaching professional development was generated through lived academic leadership and teaching practice in and around the unit (Roxa \& Martensson, 2011). The agile workshop was combined with the unit orientation prior to the semester and was designed to have immediate and relevant application.

The learning development approach was, therefore, in alignment with theories that recognise that teaching is a professional practice informed by the social processes occurring through that practice (Boud \& Brew, 2013). Focused on a particular community of tutors within a single unit-and integrated with the unit orientation - the professional development was framed not as a mechanism to meet university measures of teaching quality but as a tool to support tutors to develop their teaching practice and future careers whether inside or outside their current employment. In other words, rather than approaching the challenges to embedding eMarking as a deficit manifesting in a lack of skills the agile workshop took a more holistic approach to creating a responsive team of tutors developing their professional teaching practice and leadership in relation to technology, ongoing change and their future careers to ensure high-quality student learning experiences. By delivering the workshop in parallel with the unit orientation it took on a just in time, just for me flavour (Roberts, Butcher, \& Brooker, 2011); the professional development was designed to appeal to tutors' desire to improve the student experience, taking the focus off top-down directives to implement specific technologies. 
In recognition of resourcing and timetabling, the workshop was delivered over two days prior to the semester and had the following learning outcomes:

a) Understand the course teaching and learning materials, strategies and environment.

b) Develop an understanding of the global knowledge economy and how this impacts on higher education and the university.

c) Recognise the need for academics to be agile teachers and adapt to change.

d) Understand frameworks and theories of change.

e) Understand intra-personal skills and strategies to positively manage working in a changing tertiary environment.

f) Understand the components of learning technologies to build confidence with eLearning tools.

The agile workshop incorporated multi-disciplinary content including: distributed leadership using the integrated competing values framework (Vilkinas \& Cartan, 2001), theories of change and change management in the context of current higher educational drivers and technology adoption, reflection on academic social and cultural beliefs, an exploration of intrapersonal skills such as self-talk and mindfulness (to manage emotional responses to technology failures or challenges), peer learning with successful early adopters, and an understanding of technology system components as opposed to how to use a program to support a shift in thinking from mastery to adaptive responses to technology use (Harris, Price, Flavell, Penman, \& Peterson, 2015). Furthermore, the professional development incorporated useful applications and tips and importantly included practical strategies when eLearning technologies did not go to plan. The associated activities used a combination of small group discussions, videos, group activities using iPads, and presentations from the facilitators $(\mathrm{CH}, \mathrm{CP}$, and $\mathrm{HF})$ and outside speakers with relevant expertise. Participants were encouraged to adopt a generation flux response to the changing world of work: (1) become a habitual skill hoarder, (2) commit to a daily dose of learning, (3) mix up their media, and (4) take timeout to rest (Next Avenue, 2012).

\section{Method}

\section{Setting}

As established above, the study took place in a large faculty of health sciences at an Australian university within the context of a common inter-professional first year which required the unit coordinator to increase and constantly update eLearning (and other) technologies to effectively manage the large student cohort and ensure equitable learning experiences.

\section{Study design}

An exploratory case study approach (Yin, 2009) was chosen to examine the impact of the agile teaching professional development and determine its relevance. This approach to the study was seen as applicable due to its capacity to provide an in-depth exploration of a phenomenon in context using multiple data points (quantitative and qualitative) to answer the research questions (Steinert et al., 2016). To add rigor, a quasiexperimental design with an intervention group and a comparative control group was adopted (Creswell, 2012). Pre and post online questionnaires were administered to participants in both groups to evaluate attitudes and experiences relating to technology use in teaching and learning. The questionnaires were selected to explore ICT use and changes in attitudes, beliefs, and perceptions over the course of one semester as a result of teaching experiences (both groups) and the professional development (the intervention group alone). Measures relating to individual attitudes, perceptions, and beliefs were chosen as the majority of participants were casual teaching staff with little or no control over course design and thus lacked the capacity to implement eLearning technologies within the study's context (the interprofessional core units). Additionally, the adaptation and use of existing validated measures on technology acceptance was designed to increase the study’s credibility (Bryman, 2012). Qualitative measurement of the intervention groups' experiences following the professional development was captured using semistructured interviews. Two focus groups were conducted with participants of the professional development (member checking) to confirm the findings from the interviews. Ethical approval for this study was obtained from the university's human research ethics committee and the study was conducted in accordance with ethical standards for research. 


\section{Participants}

The research targeted tutors within the inter-professional common first-year; the intervention group was from one course whilst the control group participants were from two other common first year courses. Only the intervention group participated in the 2-day professional development during the university's orientation week (although the same workshop was delivered to the control group at a later date but not as part of the study). The size and nature of the course meant that the intervention participants taught in teams throughout the semester (two tutors per class). Although there were initially 37 respondents, participation in the study involved 29 tutors across three inter-professional first-year courses as not all respondents had complete data sets. The intervention group consisted of 22 participants (20 female; 2 male), the control group had 7 participants (6 female; 1 male). Of the 22 intervention group participants, 16 went on to participate in a semi-structured interview and a further 10 attended a focus group session.

While the age of the participants in the intervention group was spread across all age ranges, the control group was clustered in the 26 - 40 years groupings (Table 1). Reflective of the inter-professional teaching strategy for the common first-year units, the participants represented different health care professions, had varying amounts of teaching experience (3.6 \pm 4.8 years; range $0-23$ years), and varying employment contracts though the majority were on casual contracts (Table 1).

\section{Participants' technology exposure and type of devices}

Frequency and type of participants' technology use

Pre-intervention the majority of participants reported spending more than three hours per day using a device (intervention group 86\%; control group 63\%). Traditional computers (desktop or laptop) were the most used devices by participants (intervention group 82\%; control group 63\%), with $77 \%$ of the intervention group and $50 \%$ of the control group reporting using computers for more than 3 hours per day. In addition to computers, all participants had access to and used at least one mobile device daily. Only $11 \%$ of the intervention group did not use a smartphone and 23\% of the intervention group; $13 \%$ of the control group reported that they never used a tablet or eReader. Participants performed a variety of activities across a number of devices. For example, communication and social interaction activities were performed on a variety of devices with $91 \%$ of the intervention group participants using 2 or more devices for email, and $86 \%$ engaging in some form of social networking. All intervention group participants used devices for producing/editing documents and photos; 91\% produced/edited video; 64\% played games; 50\% used devices for reading eBooks; 36\% used devices for listening and creating music. These results indicate that the majority of intervention group participants used their devices for more than just the consumption of digital materials; they actively engaged in productivity activities as well.

Table 1

Participant demographics

\begin{tabular}{llrr}
\hline & & $\begin{array}{c}\text { Intervention } \\
(n=22)\end{array}$ & $\begin{array}{r}\text { Control } \\
(n=7)\end{array}$ \\
\hline Age (years) & $20-25$ & $18 \%(4)$ & \\
& $26-30$ & $27 \%(6)$ & $14 \%(1)$ \\
& $31-35$ & $9 \%(2)$ & $57 \%(4)$ \\
& $36-40$ & $5 \%(1)$ & $29 \%(2)$ \\
& $41-45$ & $18 \%(4)$ & \\
& $46-50$ & $18 \%(4)$ & \\
& $56-60$ & $5 \%(1)$ & $57 \%(4)$ \\
& Casual/sessional & $82 \%(18)$ & $14 \%(1)$ \\
& Fixed term (part-time) & & \\
& Fixed term (full-time) & $9 \%(2)$ & $14 \%(1)$ \\
& Ongoing (part-time) & $9 \%(2)$ & $14 \%(1)$ \\
\hline
\end{tabular}




\section{Materials}

Online questionnaires

Data collection was undertaken in both the control and intervention groups using online pre and post questionnaires developed through a review of the literature. The same questionnaire structure was used for the initial and follow-up data collection phases (at the end of the semester teaching period) and comprised self-reported items covering demographic characteristics, patterns of technology use, technology acceptance and perceptions (barriers and enablers), and beliefs and intentions. The question format was primarily fixed-choice but included some open-ended text options.

\section{Patterns of technological use}

Items relating to patterns of technology use were developed for the purposes of this study; participants were given definitions of information technology, learning technologies, and information and communication technologies, and asked four questions relating to their use including devices owned or had access to use, frequency and duration of use, and types of activities performed.

\section{Technology acceptance}

Using 13 out of the 16 TAM subscales developed by Venkatesh and Bala (2008) participants were asked about their level of technology acceptance. The subscales used are listed in Table 3 . The remaining subscales were not included as their content was already covered by other items or did not address the study objectives. All items were answered on a 5-point Likert scale from (1) strongly disagree to (5) strongly agree.

Semi-structured interviews and focus groups

Participants in the intervention group were invited to a semi-structured interview to explore their attitudes to technology, their experience attending the professional development, and whether there had been any changes or intended changes in behaviour as a consequence of participation. This was followed by two focus groups several weeks later open to anyone who had participated in the agile workshop to check the themes emerging from the interviews.

\section{Data analysis}

The quantitative data was analysed using the Statistical Package for the Social Sciences (SPSS v20). Descriptive statistics were used to describe sample characteristics and patterns of technology use. Due to the small sizes and a large discrepancy in sample sizes between groups, it was decided that non-parametric tests would provide a more conservative estimate of the relationships between variables to meet the aims and objectives of the study. Independent sets of data were analysed using Mann-Whitney U tests and paired sets of data were analysed using Wilcoxon signed rank tests.

Qualitative thematic analysis was conducted using NVIVO (v10) (QSR International, 2013) and an inductive, holistic, and all-encompassing approach. All 16 interviews were analysed, although saturation of themes was achieved by interview 11. For the process of analysis, the conventions of Braun and Clarke (2006) were followed. In the first phase, initial themes were defined using extracts derived from all interview data. Data extracts were coded broadly (e.g., what does the data extract mean at a physical, physiological, psychological, social, environmental, and/or spiritual level) to capture specific meaning, key, and/or contextual information. In the second phase, once all the interviews were coded, and the initial themes developed, the coder (SP) reviewed all themes, merging similar ones together and grouping related themes under larger categories. Themes were checked twice throughout coding with the researcher who conducted the interviews and focus groups (HF), and the larger categories were checked using the focus group participants $(n=10)$. The review by team members $(\mathrm{CH}, \mathrm{CP}, \mathrm{HF}$, and SP) and participants did not suggest any changes were required. 
Table 2

Terminology used throughout the qualitative results section

\begin{tabular}{ll}
\hline Number of participants & Categories of participant numbers \\
\hline 16 & All \\
$15-11$ & Most \\
$10-6$ & Many \\
$5-1$ & Some/few \\
0 & None \\
\hline
\end{tabular}

\section{Results}

\section{Quantitative data: Participants' attitudes to technology}

\section{Participants' reported purpose of using technology in higher education}

Intervention group participants reported that learning technologies were relevant to addressing issues such as increased student access to learning materials (86\% of participants); improving student learning outcomes (73\% of participants); making teaching more effective (73\% of participants); making assessment more efficient (82\% of participants); engaging students (82\% of participants); and facilitating communication (59\% of participants). These reasons for technology use were in contrast to personal enjoyment (32\% of participants) and the desire to reduce the cost of education (27\% of participants).

Internal factors, intention to use learning technologies and external factors related to participants' technology use

There were no significant differences between the intervention and the control groups on any of the TAM subscales at the initial (pre-scores) survey (Table 3). Significant differences were found between pre and post intervention scores on five subscales for the intervention group, whereas there were no significant differences for the control group (Table 3). Considering the subscales that reflect internal factors influencing the use of learning technologies, the intervention group showed small changes in all of the subscales that would suggest an overall increased level of confidence and positive approach to technologies. Although not statistically significant, there was a slight decrease in technology anxiety and increases in the computer self-efficacy, computer playfulness, and perceived enjoyment subscales. There was also a statistically significant increase in the mean for the perceived ease of use subscale. Considering the items in this subscale it appears that the intervention group perceived a change (decrease) in the amount of mental effort required to interact with learning technologies (initial $4.3 \pm 1.8$; follow-up $5.0 \pm 1.7$ ) and they reported a more favourable response to the statement: "I find learning technologies easy to use" (initial 4.6 \pm v1.2; follow-up $5.2 \pm 1.2$ ). There was very little change in their response to the third item: "I find it easy to get learning technologies to do what I want them to do” (initial 5.1 \pm 1.3 ; follow-up $5.2 \pm 1.3$ ).

Three of the TAM subscales reflect factors likely to influence the participants' intentions to use learning technologies in their teaching and interactions with students. For the intervention group, there was no significant change in the perceived usefulness subscale which asked about their perceptions of how using learning technologies improved their teaching, job performance, or effectiveness as a teacher. The intervention group participants generally agreed (score of $6=$ agree) with the statements in the behavioural intentions subscale and there was no significant change in the subscale score following the intervention. There was, however, a statistically significant decrease in the voluntariness score. Considering the items in the voluntariness subscale, the intervention group initially appeared ambivalent that their use of learning technologies was voluntary (initial $4.0 \pm 1.7$; follow-up $3.9 \pm 1.6$ ) but recognised the requirements for the use of learning technologies within the course. They demonstrated this by disagreeing with the statement: "The course coordinator does not require me to use learning technologies in my teaching" (initial 2.6 \pm 1.2 ; follow-up $1.9 \pm 0.8$ ), to a similar statement about their Head of Department (initial $2.9 \pm 1.2$; follow-up 2.9 \pm 1.3 ), and to the item "Although they might be helpful, using learning technologies is certainly not compulsory for my teaching and interactions with students" (initial $2.9 \pm 1.2$; follow-up $2.1 \pm 0.8$ ). The TAM contains five subscales that evaluate external factors such as image, desire to fit in, the influence of people in positions of power on the participants' use of technologies. Three of these subscales showed statistically significant differences between initial and follow-up measures. 
The perception of external control subscale consists of four items. Intervention group participants shifted from $4.7 \pm 1.3$ to $5.1 \pm 1.4$ for the first item indicating that they were beginning to agree that they had some control over the use of learning technologies in their teaching and interactions with students. Following the intervention, participants appeared to be more aware of the resources (Item 2: initial $5.4 \pm 1.3$; follow-up $5.8 \pm 0.8$ ) and the opportunities and knowledge required to use learning technologies (Item 3: initial $5.2 \pm$ 1.2; follow-up $5.6 \pm 1.1$ ). The fourth item measures perceptions of compatibility of learning technologies with other types of technologies used by participants. Initially, intervention group participants disagreed somewhat $(3.3 \pm 1.2)$ with this statement and shifted towards disagree at follow-up $(2.8 \pm 1.1)$ indicating that there was minimal potential disharmony between their personal and work uses of technology.

The subjective norm subscale measures the influence of the people in the participants personal and work circles on their own use of learning technologies. Intervention group participants tended to agree with the two statements that the people who influence their behaviour (initial $4.8 \pm 0.9$; follow-up $5.6 \pm 1.1$ ) and the people who are important to them (initial $4.7 \pm 1.0$; follow-up $5.6 \pm 1.1$ ) think that they should use learning technologies. They also agreed that the institution (initial $5.3 \pm 0.9$; follow-up $5.7 \pm 0.8$ ) and senior management (initial $4.5 \pm 1.3$; follow-up $4.7 \pm 1.3$ ) supported the use of learning technologies.

The third subscale that showed statistically significant differences for the intervention group between initial and follow-up measures is the results demonstrability subscale. This subscale consists of statements about the respondent's ability to explain learning technologies to others. Following the professional development, the intervention group tended to agree more strongly that they could tell others about the usefulness of learning technologies (initial $5.2 \pm 1.1$; follow-up $5.9 \pm 0.8$ ), the consequences of their use (initial $5.3 \pm 0.8$; follow-up $5.8 \pm 0.8$ ), and why learning technologies may or may not be beneficial (initial $3.3 \pm 1.3$; followup $2.6 \pm 1.0$ ). Participants also agreed more strongly that the results/outcomes of using learning technologies were apparent to them (initial $5.4 \pm 1.0$; follow-up $5.9 \pm 0.7$ ).

Table 3

TAM subscale scores for both groups at initial and follow-up

\begin{tabular}{|c|c|c|c|c|}
\hline \multirow[b]{2}{*}{ TAM subscale } & \multicolumn{2}{|c|}{ Intervention Group } & \multicolumn{2}{|c|}{ Control Group } \\
\hline & Initial & Follow-up & Initial & Follow-up \\
\hline \multicolumn{5}{|l|}{ Internal factors } \\
\hline Technology anxiety & $2.5(1.3)$ & $2.4(1.2)$ & $2.9(1.4)$ & $2.9(1.3)$ \\
\hline Computer self-efficacy & $5.7(0.7)$ & $5.8(0.6)$ & $5.4(0.8)$ & $5.5(0.8)$ \\
\hline Perceived ease of use & $4.7(1.3)$ & $5.1(1.2)^{*}$ & $4.6(1.7)$ & $5.0(0.8)$ \\
\hline Perceived enjoyment & $5.1(1.1)$ & $5.4(0.9)$ & $4.9(1.2)$ & $5.3(1.4)$ \\
\hline Computer playfulness & $4.6(1.4)$ & $5.0(1.0)$ & $4.0(1.5)$ & $4.1(1.4)$ \\
\hline \multicolumn{5}{|l|}{ Intention to use LT } \\
\hline Perceived usefulness & $5.8(0.7)$ & $5.7(0.9)$ & $5.3(1.1)$ & $5.8(1.0)$ \\
\hline Voluntariness & $3.1(1.1)$ & $2.7(0.8)^{*}$ & $2.7(0.9)$ & $3.2(1.2)$ \\
\hline Behavioural intention & $6.1(0.7)$ & $6.0(0.8)$ & $5.6(1.2)$ & $6.0(1.0)$ \\
\hline \multicolumn{5}{|l|}{ External Factors } \\
\hline Perception of external control & $5.0(1.1)$ & $5.4(0.8)^{*}$ & $4.7(1.0)$ & $5.0(1.2)$ \\
\hline Subjective norm & $4.8(0.7)$ & $5.4(0.9)^{*}$ & $4.9(0.5)$ & $5.1(0.8)$ \\
\hline Image & $3.6(1.1)$ & 3.7 (1.3) & $4.0(1.0)$ & $4.5(0.9)$ \\
\hline Job relevance & $5.8(0.8)$ & $6.0(0.7)$ & $5.7(1.2)$ & $6.0(0.9)$ \\
\hline Results demonstrability & $5.2(0.9)$ & $5.7(0.6)^{*}$ & $5.0(0.9)$ & $5.1(0.6)$ \\
\hline
\end{tabular}

* Indicates a statistically significant difference, $p<.05$

\section{Qualitative data: Change relating to the professional development, workplace, teaching and technology use experiences}

Qualitative findings supported the changes suggested by the quantitative data; following positive experiences with the professional development the intervention group reported learning varied teaching strategies (e.g., Fishbowl, You-Tube technology, goal setting, and the flipped classroom) and new technologies. They also valued learning about/or having the opportunity to discuss faulty thinking and reflective writing, and learn or validate their own views of self (e.g., being an early adopter of technologies). Direct data reports or deduction from content of the data showed that a few participants reported they did not experience change or experienced minimal change in specific areas such as the application knowledge 
or use and/or faulty thinking or teaching practice. These participants noted that they were already aware of these things and/or did not have the opportunity to apply change due to the structured nature of the first year course. However, all participants noted that they had experienced cognitive, emotional, and/or behavioural changes during and/or since attending the professional development as documented in Figure 1.

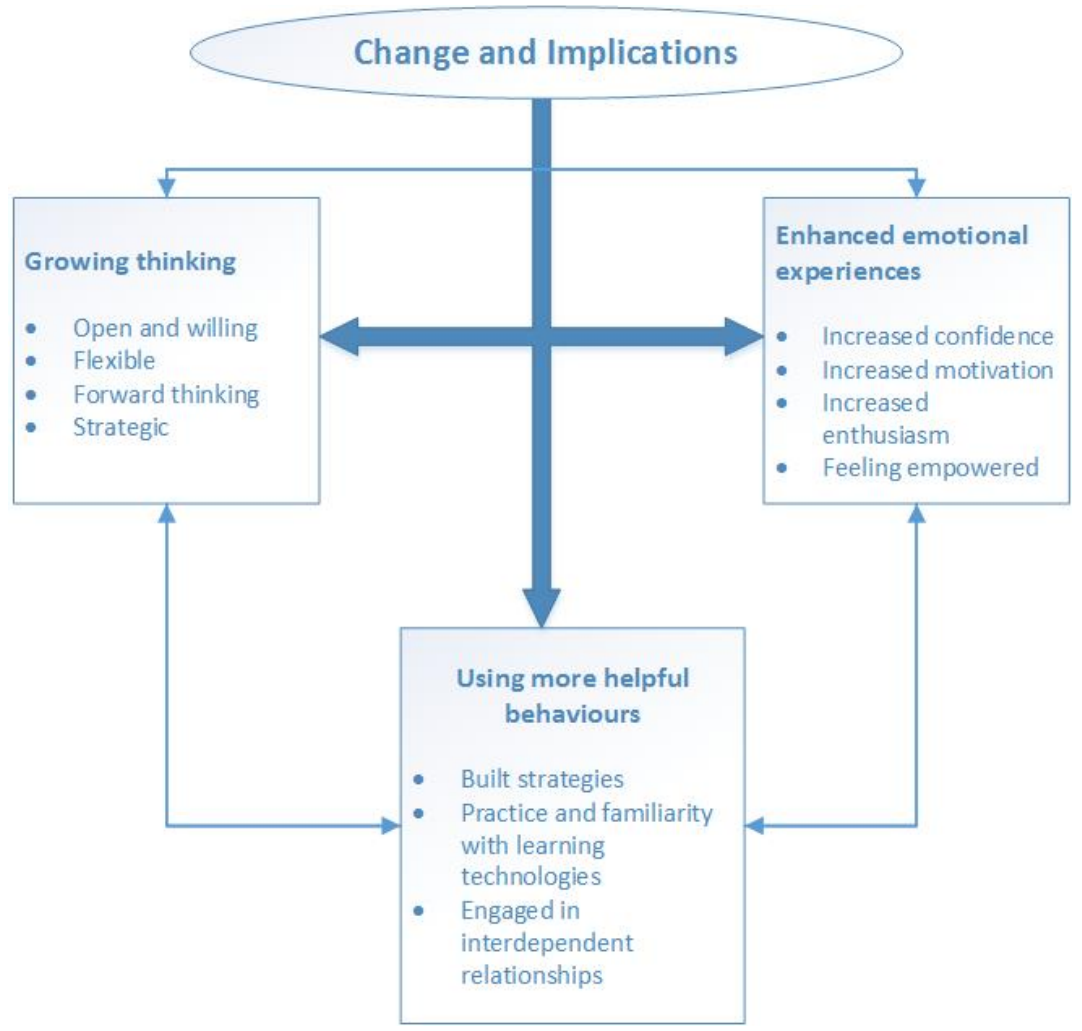

Figure 1. Themes and their relationship

\section{Growing thinking}

Since attending the professional development, many participants seemed more open and willing to engage in new thinking to resolve challenges, along with recognising their personal strengths and/or barriers that enabled them to manage these proactively. Participants thought about resolutions to problems that could impede effective teaching and engaged in strategic thinking to develop their capability. Further, participants' resolution involved thinking about working with, rather than against, challenges. They achieved this by reflecting on past experiences to develop effective contingency plans to overcome present challenges and/or prepare plans to resolve potential challenges. These statements highlight some such strategies:

[M]ore willing to... sit back...talk up at times and be agile in that kind of relationship.

It has all gone fine...even with the team teaching...just turn up and we kind of go, "Do you want to do that, do you want to do that?"- cool—or we'll just go with the flow. So I've just kind of done it with the rest of the unit [course] ... there has been content that I'm not $100 \%$ sure about but I'll turn up early to quickly chat to that tutor and they are like, “yes, I'll cover that bit for you and you do that bit”. They're not big problems, you know, it can all be solved.

\section{Enhanced emotional experiences}

Some participants noted, having positive encounters with technology, successfully resolving technology challenges, helping others, and/or developing skills over time, enhanced their emotional experiences of and self-confidence, sense of security, and motivation. Positive experiences with technologies related to participants' use of improved systems (e.g., GradeMark@) and/or other needs (e.g., using Lost on Campus to navigate) gained. Positive technology encounters including systems running smoothly and not crashing, 
and being able to source and use new technology (e.g., setting up two screens, Lost on Campus application, iPads, and smartphones) supported their achievement of teaching and/or personal goals and enabled development.

I enjoyed the challenge and I think I enjoyed thinking about how far I've come with respect to my approach to using computers in teaching and all that sort of stuff, compared to where I'm at now. I think I've come quite a long way, personally, because I was probably someone who prior to, say probably two or three years ago, would have considered myself, quite proudly, fairly Amish when it comes to the use of technology. As part of my identity even, I didn't really want to have anything much to do with them, but now I've sort of realised that there are good and bad things about them and to get the good you have to embrace the whole lot, whether you like it or not. Now I would rarely be without my iPad.

All participants noted that they had developed their confidence, excitement, enthusiasm, and/or motivation and feelings of empowerment, happiness, and value from having support of others and achieving intended outcomes in teaching and/or the use of technology.

[S]o it's opened my eyes to what technology can do and technology is not as scary as I think it is and then it can make the teaching really dynamic and diverse rather than just someone prattling away. That's really opened my eyes in terms of what can be done.

Even just the empowerment side of the session, obtaining knowledge, developing some skills and feeling empowered to go out and make the classroom an engaging space.

Using more helpful behaviours

Using more helpful behaviours were changes that assisted participants to manage workplace stress and reduced the potential for them to engage in unhelpful thinking, which sustained their motivation and commitment to achieving excellence in teaching. Some participants noted working towards using new technologies outside the teaching space to get practice and familiarity, which would assist them to incorporate these in their future teaching. Some participants noted being motivated to pursue teaching as a career (casual staff) and build on the learning they had undertaken in the professional development (e.g., do mindfulness relaxation training). A few participants were planning to be more prepared to manage challenges and/or facilitate student learning. The following statement highlights some such experiences:

[U]sually it was already up and set and I'd get the person-whoever was in the class before me- to just quickly show me how it worked ... there were a few issues with how it was going to happen to start off ... [by] week 3 or 4 they had found a system that worked for everyone ... teething problems at the beginning ... just par for the course ... just expect that now so I'm never especially upset if things aren't working straight off the bat.

Participants engaged in interdependent relationships when working with others. In this, a participant noted making a concerted effort not to establish dependent working relationships to reduce their reliance on others to resolve technology challenges.

I probably shouldn't tell you ... I am paired with two agile young teachers who are absolute whizzes on the computer [used to step back and let them do it] now trying to take some control and say, "No, today I will, you know, set up the computer”... I have been quite lazy ... I guess for me I'm taking more responsibility or seeing things a little differently, and I guess - trust-because in this unit [course] you're not always sure what's coming week to week.

Participants also noted working: through their unhelpful thinking, frustration and/or annoyance; on being open-minded to find the "silver lining" in a challenge; and to develop realistic and achievable goals to improve their skills and become more creative and resourceful in using what was available when technology challenges presented. The following statements highlight some strategies:

I have a crack at using it ... incrementally building my knowledge and confidence ... there's so much and just doing a little bit at a time rather than trying to explore everything ... just 
been learning Blackboard ... as I go ... just needing a coach ... got to and have five minutes just to clarify something and then apply it.

I know they had issues with Blackboard being down and when I saw their emails I thought I'll just wait till it works.

Faulty thinking I found quite useful ... I do a lot of those faulty thinking things ... now I've realised that I can recognise when it's happening and then work towards trying to shift that way of thinking. So that was good. I liked that.

I’ve just fallen in love with DropBox which I don't think was introduced but that's something that I probably felt more confident to use because of my colleagues at that agile course talking about it.

Moreover, all participants reported actions that they had taken or intended to take in the future, indicating their commitment to using technology. This included wanting to explore, learn, download, and/or use applications that they encountered during training (e.g., Pinterest or Scoop.it!) alongside other technologies (e.g., iPad and You-Tube clips) into future teaching and/or beyond teaching for their personal use. For some participants, these plans were initiated independently from the challenges that they or others had experienced. Overall, the findings suggested that cognitive changes enabled participants to acquire new knowledge, refresh and expand their creativity and existing strategies, and/or themselves. Further, the findings showed that these cognitive changes occurred alongside emotional and behavioural changes; and, these three types of changes seemed to influence each other (Figure 1).

\section{Discussion}

The multidisciplinary agile professional development—with this participant group—appeared to positively impact on a commonly identified challenge to learning technology uptake in higher education. That is, it showed the capacity to increase confidence and perceived ease of use (Watty et al., 2016) for the eLearning (and related) technologies addressed through the workshop. In addition, the qualitative data suggests that the professional development increased technological confidence and built capacity to manage challenges when technology did not go to plan. Interestingly, while $50 \%$ of the intervention group reported (prior to the agile workshop) using a device for reading eBooks, a moderate proportion (36\%) did not engage in game play on any device. Engaging in recreational activities such as reading for pleasure, playing games, or using social media are potential indicators of overall comfort with technology as these are self-selected rather than required uses of technology. The subsequent increase in curiosity and confidence following the intervention suggests some capacity of the professional development to impact on participants' attitudes, which has been identified as a central barrier to eLearning adoption (Schneckenberg, 2009). Of note, according to Schneckenberg (2009), professional development for eLearning must address the needs and interests of academic staff and, to achieve this, requires a shift from formal ICT training. The agile teaching workshop attempted to do this through looking at how adaptive, life-long learning attitudes towards technology use-within a leadership framework (Vilkinas \& Cartan, 2001)—could be fostered in academics. Like graduates, academics need to develop capacity to build their resilience for a changing workplace and, rather than develop competence for a specific technology, know how to find solutions independently for a range of technologies. The professional learning-embedded within local teaching and learning regimes (Dusick \& Yildirim, 2000)—differed from traditional approaches to ICT and/or eLearning development by being located in practice and encouraging participants to become early adopters with the express purpose of improving student learning and supporting their own career development (Howard, 2013). By providing strategies to find solutions, addressing their emotional response to technology challenges, reflecting on their habitual thinking about technology use at work, the agile workshop aimed to bolster interest in eLearning (Sheehy, Marcus, Costa, \& Taylor, 2006).

Whilst the agile teaching approach to professional development appeared to improve academic attitudes towards, and confidence with, eLearning technologies it is important to consider that individuals require a supportive organisational culture to embed technology (Zhu, 2015). Regardless of how committed individuals are, workload and other barriers also need to be examined (Gregorya \& Lodge, 2015). This is an important consideration in the context of this study, where the local leadership (i.e., course coordinator) provided strong leadership to provide relevant professional learning for largely casual tutors those typically 
overlooked for professional development beyond introductory courses to teaching (Hamilton, Fox, \& Mitchell, 2013). Approaches to embedding eLearning technologies, therefore, need to address not just individual capacity building (micro level) but also the organisational (macro level) factors that impact on technological innovation (Singh \& Hardaker, 2014). These include, but are not limited to, how academic identity comes into play, whether eLearning (i.e., teaching) innovation is meaningfully valued, leadership practices and the policy context (i.e., whether policies inhibit or enable eLearning innovation). Additionally, universities need to interrogate the value and relevance of each eLearning technology and consider the workload implications for teaching staff.

\section{Limitations}

The majority of the study participants were casual tutors and, therefore, had little opportunity to embed eLearning innovations into their teaching practice within study's context. The approach to professional development utilised in this study thus needs to be tested on academics with greater capacity to embed of eLearning technologies and from a broader range of disciplines. It is possible that the largely casual participant cohort was more responsive due to the general lack of professional development and support offered to casual academics (Hamilton et al., 2013). Further research needs to be conducted to measure the impact of the professional development on student outcomes.

\section{Conclusion}

The two-day agile teaching professional development combined multi-disciplinary content with the aim of assisting academics to become more adaptive and agile when using technology for teaching and learning. Specifically, the development opportunity combined approaches from leadership development (e.g., distributed leadership, the ICVF, theories of change and change management, and self-talk and mindfulness), peer learning with early adopters of technology, and practical knowledge about technology system components (rather than how to use a technology). The professional development provided participants with an understanding of the drivers for educational technology use in higher education. Experiential learning underpinned the activities which provided opportunities to engage with unfamiliar technologies and reflect on responses, attitudes, and beliefs. Results indicate that the professional development impacted positively on participants with the intervention group showing an overall increased level of confidence and positive approach to technology with a significant increase in perceived ease of use. Qualitative data indicated participants experienced cognitive, emotional, and/or practical changes during and/or following the professional development.

\section{Acknowledgements}

Support for this publication has been provided by the Australian Government Office for Learning and Teaching. The views in this publication do not necessarily reflect the views of the Australian Government Office for Learning and Teaching.

\section{References}

Abeysekera, L., \& Dawson, P. (2015). Motivation and cognitive load in the flipped classroom: Definition, rationale and a call for research. Higher Education Research \& Development, 34(1), 1-14. https://doi.org/10.1080/07294360.2014.934336

Adams Becker, S., Cummins, M., Davis, A., Freeman, A., Hall Giesinger, C., \& Ananthanarayanan, V. (2017 ). NMC Horizon Report: 2017 Higher Education Edition Retrieved from https://www.nmc.org/publication/nmc-horizon-report-2017-higher-education-edition/

Agarwal, R., \& Prasad, J. (1997). The role of innovation characteristics and perceived voluntariness in the acceptance of information technologies. Decision Sciences, 28(3), 557-582. https://doi.org/10.1111/j.1540-5915.1997.tb01322.x

Allen, M. (2009). Move quickly to adopt new approaches. Retrieved from http://www.knowledgenetworklearning.net/concepts/pedagogy/teachingagility/

Arroway, P., Morgan, G., O'Keefe, M., \& Yanosky, R. (2016). Learning analytics in higher education. Research report. Retrieved from https://library.educause.edu/ /media/files/library/2016/2/ers1504la.pdf 
Bakhshi, H., Frey, C. B., \& Osborne, M. (2015). Creativity vs. robots: The creative economy and the future of employment. Retrieved from https://www.nesta.org.uk/sites/default/files/creativity_vs._robots_wv.pdf

Barber, M., Donnelly, K., \& Rizvi, S. (2013). An avalanche is coming: Higher education and the revolution ahead. Retrieved from

http://www.ippr.org/files/images/media/files/publication/2013/04/avalanche-iscoming_Mar2013_10432.pdf?noredirect=1

Batson, T. (2011). Faculty 'buy-in' - to what? Campus Technology. Retrieved from https://campustechnology.com/articles/2011/04/06/faculty-buy-in-to-what.aspx

Bayne, S. (2015). What's the matter with 'technology-enhanced learning'? Learning, Media and Technology, 40(1), 5-20. https://doi.org/10.1080/17439884.2014.915851

Birch, D., \& Burnett, B. (2009). Bringing academics on board: Encouraging institution-wide diffusion of e-learning environments. Australasian Journal of Educational Technology, 25(1), 117-134. https://doi.org/10.14742/ajet.1184

Blin, F., \& Munro, M. (2008). Why hasn’t technology disrupted academics’ teaching practices? Understanding resistance to change through the lens of activity theory. Computers \& Education, 50(2), 475-490. https://doi.org/10.1016/j.compedu.2007.09.017

Boud, D., \& Brew, A. (2013). Reconceptualising academic work as professional practice: Implications for academic development. International Journal for Academic Development, 18(3), 208-221. https://doi.org/10.1080/1360144X.2012.671771

Braun, V., \& Clarke, V. (2006). Using thematic analysis in psychology. Qualitative Research in Psychology, 3(2), 77-101. https://doi.org/10.1191/1478088706qp063oa

Brewer, M., Flavell, H., Davis, M., Harris, C., \& Bathgate, K. (2014). Ensuring health graduates' employability in a changing world: Developing interprofessional practice capabilities using a framework to inform curricula. Journal of teaching and learning for graduate employability, 5(1), 2946. https://doi.org/10.21153/jtlge2014vol5no1art566

Bryman, A. (2012). Social research methods (4th ed.). New York, NY: Oxford University Press.

Bukari, H. (2016). ICT skills evaluation of faculty members in Kuwait; preliminary findings. Information Development, 32(4), 777-798. https://doi.org/10.1177/0266666914568796

Creswell, J. W. (2012). Educational research: Planning, conducting, and evaluating quantitative and qualitative research (4th ed.). Boston, MA: Pearson.

Davis, C. (2013). Flipped or inverted learning: strategies for course design. In E. G. Smyth \& J. X. Volker (Eds.), Enhancing instruction with visual media: Utlizing video and lecture capture (pp. 241-265). Hershy, PA: IGI Global.

Davis, F. (1989). Perceived usefulness, perceived ease of use, and user acceptance of information technology. MIS Quarterly, 13(3), 319-340. https://doi.org/10.2307/249008

Debuse, J. C. W., Lawley, M., \& Shibl, R. (2008). Educators' perceptions of automated feedback systems. Australasian Journal of Educational Technology, 24(4), 374-386. https://doi.org/10.14742/ajet.1198

Deneen, C., \& Boud, D. (2013). Patterns of resistance in managing assessment change. Assessment \& Evaluation in Higher Education, 39(5), 577-591. https://doi.org/10.1080/0262938.2013.859654

Drent, M., \& Meelissen, M. (2008). Which factors obstruct or stimulate teacher educators to use ICT innovatively? Computers \& Education, 51(1), 187-199. https://doi.org/10.1016/j.compedu.2007.05.001

Dusick, D. M., \& Yildirim, S. (2000). Faculty computer use and training: Identifying distinct needs for different populations. Community College Review, 27(4), 33-47. https://doi.org/10.1177/009155210002700403

Englund, C., Olofsson, A. D., \& Price, L. (2017). Teaching with technology in higher education: Understanding conceptual change and development in practice. Higher Education Research \& Development, 36(1), 73-87. https://doi.org/10.1080/07294360.2016.1171300

Gregorya, M. S.-J., \& Lodge, J. M. (2015). Academic workload: the silent barrier to the implementation of technology-enhanced learning strategies in higher education. Distance Education, 36(2), 210-230. https://doi.org/10.1080/01587919.2015.1055056

Gronn, P. (2002). Distributed leadership as a unit of analysis. The Leadership Quarterly, 13(4), 423-451. doi.org/10.1016/S1048-9843(02)00120-0

Hamilton, J., Fox, M., \& Mitchell, M. (2013). Sessional academic success: A distributed framework for academic support and development. Journal of University Teaching \& Learning Practice, 10(3), 9. Retrieved from http://ro.uow.edu.au/jutlp/vol10/iss3/9/ 
Hansen, J. (2009). Displaced but not replaced: The impact of e-learning on academic identities in higher education. Teaching in Higher Education, 14(5), 553-564. https://doi.org/10.1080/13562510903186774

Harris, C., Price, C., Flavell, H., Penman, E., \& Peterson, S. (2015). Developing academic staff capacity for agile teaching: a quasi-experimental study in implementing eMarking workflows for student assessment in a large first year health sciences unit. Retrieved from http://www.olt.gov.au/resourceeMarking-workflows-student-assessment

Howard, S. K. (2013). Risk-aversion: understanding teacher's resistance to technology integration. Technology, Pedagogy and Education, 22(3), 357-372. https://doi.org/10.1080/1475939X.2013.802995

Johnson, T., Winiewski, M. A., Kuhlemeyer, G., Issacs, G., \& Krzykowski, J. (2012). Technology adoption in higher education: Overcoming anxiety through faculty bootcamp. Journal of Asynchronous Learning Networks, 16(2), 62-72. https://doi.org/10.24059/olj.v16i2.240

Lareki, A., Ignacio, J., de Morentin, M., \& Amenabar, N. (2010). Towards an efficient training of university faculty on ICTs. Computers \& Education, 54(2), 491-497. https://doi.org/10.1016/j.compedu.2009.08.032

McNutt, L. (2010). Educational technology, innovation and habitus: what is the connection? In R. Donnelly, J. Harvey, \& K. O'Rourke (Eds.), Critical design and effective tools for e-learning in higher education: Theory into practice. Hershey, PA: IGI Global.

McWilliam, E. (2009). Teaching for creativity: from sage to guide to meddler. Asia Pacific Journal of Education, 29(3), 281-293. https://doi.org/10.1080/02188790903092787

Muzyka, J. L., \& Luker, C. S. (2016). Introduction. In J. L. Muzyka, \& C. S. Luker (Eds.), The flipped classroom (Vol. 1). Washington, DC: American Chemical Society.

Next Avenue. (2012). How to become a 'generation flux' employee. Retrieved from https://www.forbes.com/sites/nextavenue/2012/11/07/how-to-become-a-generation-flux-employee/ 680c5c1e6412

Peseta, T., Barrie, S., \& McLean, J. (2017). Academic life in the measured university: Pleasures, paradoxes and politics. Higher Education Research \& Development, 36(3), 453-457. https://doi.org/10.1080/07294360.2017.1293909

Price Waterhouse Coopers and Australian Higher Education Industry Association. (2016). The Australian higher education workforce of the future. Retrieved from http://www.aheia.edu.au/news/highereducationworkforce-of-the-future-167

QSR International. (2013). NVIVO 10. Retrieved from www.qsrinternational.com/products_nvivo.aspx

Razmov, V., \& Anderson, R. (2006). Experiences with agile teaching in project-based courses. Paper presented at the 113th Annual ASEE Conference and Exposition, Chicago, IL. Retrieved from http://www.cs.washington.edu/research/edtech/publications/RA06-ASEE_AgileTeaching.pdf

Rienties, B., Brouwer, N., \& Lygo-Baker, S. (2013). The effects of online professional development on higher education teachers' beliefs and intentions towards learning facilitation and technology. Teaching and Teacher Education, 29, 122-131. https://doi.org/10.1016/j.tate.2012.09.002

Roberts, S., Butcher, L., \& Brooker, M. (2011). Clarifying, developing and valuing the role of unit coordinators as informal leaders of learning in higher education. Retrieved from http://www.tlc.murdoch.edu.au/project/ucall/docs/FinalReport_UCaLL_Nov10.pdf

Roxa, T., \& Martensson, K. (2011). Understanding strong microcultures: An exploratory study. Retrieved from https://www.mah.se/upload/Medarbetare/akademisktlararskap/dokument/Academicmicrocultures.pdf

Sadler, K., Selkrig, M., \& Manthunga, C. (2017). Teaching is opening up spaces to expore academic work in fluid and volatile times. Higher Education Research \& Development, 36(1), 171-186. https://doi.org/10.1080/07294360.2016.1171299

Schneckenberg, D. (2009). Understanding the real barriers to technology-enhanced innovation in higher education. Educational Research, 51(4), 411-424. https://doi.org/10.1080/00131880903354741

Sharpe, R., \& Oliver, M. (2007). Supporting practitioners' design for learning. In H. Beetham \& R. Sharpe (Eds.), Rethinking pedagogy for a digital age: Designing and delivering e-learning. Hoboken, NJ: Routledge.

Sharrock, G. (2017). Organising, managing and leading 21st century universities. In R. James, S. French, \& P. Kelly (Eds.), Visions for Australian tertiary education (pp. 27-40). Melbourne: Melbourne Centre for the Study of Higher Education. 
Sheehy, P., Marcus, G., Costa, F., \& Taylor, R. (2006, December). Implementing e-learning across a faculty: factors that encourage uptake. Paper presented at the 23rd ASCILITE Conference, Sydney. Retrived from http://www.ascilite.org/conferences/sydney06/proceeding/pdf_papers/p120.pdf

Singh, G., \& Hardaker, G. (2014). Barriers and enablers to adoption and diffusion of eLearning: A systematic review of the literature. Education and Training, 56(2/3), 105-121. https://doi.org/10.1108/ET-11-2012-0123

Steinert, Y., Mann, K., Anderson, B., Garnett, B. M., Centeno, A., Naismith, L., ... Dolmans, D. (2016). A systematic review of faculty development initiatives designed to enhance teaching effectiveness: A 10-year update: BEME Guide No. 40. Medical Teacher, 38(8), 769-786. https://doi.org/10.1080/0142159X.2016.1181851

Teo, T. (2011). Factors influencing teachers' intention to use technology: model development. Computers \& Education, 57(4), 2432-2440. https://doi.org/10.1016/j.compedu.2011.06.008

The Institute for the Future (2017). Technology horizons: From an internet of information to an internet of actions. Retrieved from http://www.iftf.org/fileadmin/user_upload/downloads/th/2017_IFTF_TH_ResearchAgenda.pdf

Venkatesh, V., \& Bala, H. (2008). Technology acceptance model 3 and a research agenda on interventions. Decision Sciences, 39(2), 273-315. https://doi.org/10.1111/j.1540-5915.2008.00192.x

Venkatesh, V., Morris, M., Davis, G., \& Davis, F. D. (2003). User acceptance of information technology: Toward a unified view. MIS Quarterly, 27(3), 425-478.

Vilkinas, T., \& Cartan, G. (2001). The behavioural control room for managers: the integrator role. Leadership and Organizational Development, 22(4), 175-185. https://doi.org/10.1108/01437730110395079

Vilkinas, T., Leask, B., \& Ladyshewsky, R. (2009). Academic leadership: Fundamental building blocks Retrieved from http://www.olt.gov.au/resource-academic-leadership-unisa-2009

Watty, K., McKay, J., \& Ngo, L. (2016). Innovators or inhibitors? Accounting faculty resistance to new educational technologies in higher education. Journal of Accounting Education, 36, 1-15. https://doi.org/10.1016/j.jaccedu.2016.03.003

Wilson-Medhurst, S., Blair, A., \& Monnet, J. (2017). Bringing about change - the challenges and opportunities for academic leaders! Blog post] Retrieved from https://www.heacademy.ac.uk/blog/bringing-about-change---challenges-and-opportunities-academicleaders

Wingo, N.P., Ivankova, N. V., \& Moss, J. A. (2017). Faculty perceptions about online teaching exploring the literature using the technology acceptance model as an organizing framework. Online Learning, 21(1), 15-35. https://doi.org/10.24059/olj.v21i1.76l

Winslett, G. (2014). Resisting innovation talk in higher education teaching and learning. Discourse: Studies in the Cultural Politics of Education, 35(2), 163-176. https://doi.org/10.1080/01596306.2012.745728

Yin, R. K. (2009). Case study research: Design and methods (4th ed.). Thousand Oaks, CA: Sage.

Zhu, C. (2015). Organisational culture and technology-enhanced innovation in higher education. Technology, Pedagogy and Education, 24(1), 65-79. https://doi.org/10.1080/1475939X.2013.822414

Corresponding author: Helen Flavell h.flavell@curtin.edu.au

Australasian Journal of Educational Technology (c) 2019.

Please cite as: Flavell, H., Harris, C., Price, C., Logan, E., \& Peterson S. (2019). Empowering academics to be adaptive with eLearning technologies: An exploratory case study. Australasian Journal of Educational Technology, 35(1), 1-15. https://doi.org/10.14742/ajet2990 